\title{
Dynamic Regulation of Extracellular Signal-Regulated Kinase (ERK) by Protein Phosphatase 2A Regulatory Subunit B56y1 in Nuclei Induces Cell Migration
}

\author{
Ei Kawahara*, Shiori Maenaka, Eri Shimada, Yoshihiro Nishimura, Hiroshi Sakurai
}

Department of Clinical Laboratory Science, Kanazawa University, Kanazawa, Japan

\begin{abstract}
Extracellular signal-regulated kinase (ERK) signalling plays a central role in various biological processes, including cell migration, but it remains unknown what factors directly regulate the strength and duration of ERK activation. We found that, among the B56 family of protein phosphatase 2A (PP2A) regulatory subunits, B56 11 suppressed EGF-induced cell migration on collagen, bound to phosphorylated-ERK, and dephosphorylated ERK, whereas B56 $\alpha 1$ and B56 $\beta 1$ did not. $B 56 \gamma 1$ was immunolocalized in nuclei. The IER3 protein was immediately highly expressed in response to costimulation of cells with EGF and collagen. Knockdown of IER3 inhibited cell migration and enhanced dephosphorylation of ERK. Analysis of the time course of PP2A-B56 $\gamma 1$ activity following the costimulation showed an immediate loss of phosphatase activity, followed by a rapid increase in activity, and this activity then remained at a stable level that was lower than the original level. Our results indicate that the strength and duration of the nuclear ERK activation signal that is initially induced by ERK kinase (MEK) are determined at least in part by modulation of the phosphatase activity of PP2A-B56 $\gamma 1$ through two independent pathways.
\end{abstract}

Citation: Kawahara E, Maenaka S, Shimada E, Nishimura Y, Sakurai H (2013) Dynamic Regulation of Extracellular Signal-Regulated Kinase (ERK) by Protein Phosphatase 2A Regulatory Subunit B56 1 in Nuclei Induces Cell Migration. PLoS ONE 8(5): e63729. doi:10.1371/journal.pone.0063729

Editor: Veerle Janssens, University of Leuven (KU Leuven), Faculty of Medicine, Belgium

Received October 3, 2012; Accepted April 5, 2013; Published May 21, 2013

Copyright: (C) 2013 Kawahara et al. This is an open-access article distributed under the terms of the Creative Commons Attribution License, which permits unrestricted use, distribution, and reproduction in any medium, provided the original author and source are credited.

Funding: Funding for this project was provided by Kanazawa University. The funders had no role in study design, data collection and analysis, decision to publish, or preparation of the manuscript.

Competing Interests: The authors have declared that no competing interests exist.

*E-mail: kawahara@staff.kanazawa-u.ac.jp

\section{Introduction}

Extracellular signal-regulated kinase (ERK) signalling plays a central role in basic biological processes of cells. A growth factor initiates a cell signal by binding to its cell surface receptor, and this is followed by activation of ERK via phosphorylation by ERK kinase (MEK) at threonine and tyrosine residues in the TEY motif (pTpYERK) [1-3]. Subsequently, ERK phosphorylates about 200 distinct substrates, ranging from transcription factors to cytoskeletal proteins, and from protein kinases to phosphatases [4]. The great diversity of ERK substrates is consistent with the diverse effects of ERK on cellular functions [5,6]. The question of how a single event is chosen among the variety of ERK-induced functions has been extensively studied, and it appears that particular cellular responses require a specific strength and duration of ERK activation [7,8]. Initially, it was thought that sustained ERK activation caused cell differentiation, while transient ERK activation led not to proliferation, but to migration $[9,10]$. However, cell proliferation also requires sustained ERK activation associated with integrin-mediated anchorage [11], which induces a gradual increase in ERK activation that is subsequently sustained [12]. A growth factor initially activates ERK rapidly and transiently [13], and then synergistic signalling from the anchorage and the growth factor induces robust and sustained ERK activation [11,14]. Thus, all anchorage-dependent cellular events, including migration [15-18], proliferation [11,19], differentiation [9] and survival [20], induced by a growth factor require sustained activation of ERK [21].

The choice of cellular outcome is presumably influenced by differences of stimulus intensity and duration or growth factor concentration. It has been shown that low concentrations of a growth factor induce cell proliferation but not cell migration, whereas higher concentrations induce cell migration on a matrix and inhibit cell proliferation [16,22]. Thus, subtle differences of growth factor stimulation produce differences in the strength and duration of ERK signalling, leading to specific biological outcomes through distinct mechanisms involving efficient ERK sensors, including phosphorylation of c-FOS protein [23]. The strength of ERK activation is mainly determined by the balance of activities of MEK and constitutively active phosphatases. It is also modulated by inactivating signals, which could originate from cross-talk with a parallel signal, a negative feedback signal or a positive feedback signal. Thus, the strength and duration of ERK activation appear to be precisely regulated by a complex network of factors, many of which remain to be fully defined.

It seems likely that phosphatases are important modulators of ERK activation. One or two phosphorylated sites in dualphosphorylated ERK could be dephosphorylated and inactivated by dual-specific mitogen-activated protein kinase (MAPK) phosphatases (MKPs) [24], tyrosine phosphatases in specialized cells $[1,2]$, and Ser/Thr protein phosphatases $[1,25,26]$. MKPs are well-known phosphatases that specifically dephosphorylate pTpYERK through a posttranscriptional negative feedback 
mechanism [24,27], which would be involved in halting ERKinduced cellular events. A protein-tyrosine phosphatase (PTP) acts as an important regulator of ERK in hematopoietic cells [28], although PTPs are dispensable for ERK regulation in other cells [29]. On the other hand, accumulating evidence indicates that PP2A has complex inhibitory and stimulatory effects on growth factor- and/or adhesion-induced signalling, in particular the ERK cascade. PP2A substrates include receptor tyrosine kinases [30,31], receptor-associated adaptor proteins [32], and all three kinases of the ERK cascade, Rafl [33-35], MEK [36,37], and ERK $[25,38,39]$. PP2A influences tumor progression [40-42]. It is also well-known to be involved in one of the most important anchorage-dependent cellular events, i.e., cell motility [43,44], which is in turn involved in cancer invasion and metastasis.

The great diversity of PP2A functions has been ascribed to the diversity of its B regulatory subunits [42]. The B regulatory subunits of PP2A heterotrimer are divided to B, B56 (B') and $\mathrm{B}^{\prime \prime}$ families. Each family consists of several gene products and splicing variants, and their individual functions and substrate specificities have been partly identified. $\mathrm{B} \alpha$ - and $\mathrm{B} \delta$-containing PP2A promote activation of ERK by dephosphorylating the Rafl inhibitory phosphorylation site [35]. It has also been found that PP2A with members of the B56 family can dephosphorylate ERK directly, and that this action is related to cell migration. Letourneux et al. [39] and Rocher et al. [45] reported that PP2A-B56 $\beta 1$, B56 $\beta 2$, B56 $\gamma 1$ and B56 2 dephosphorylate ERK directly, but they did not identify a corresponding cellular event. However, it was also reported that B56 $\gamma 1$ inhibited locomotion through dephosphorylation of paxillin or mdm2 [46,47]. p53 protein was also reported

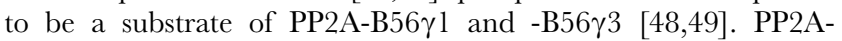
B56 $\beta 1$ dephosphorylates Pim-1 [50], TrkA [31], tyrosine hydroxylase [51], Akt1 [52,53] and Emi2 [54]. In addition, B56 $\alpha$ targets cMyc, APC, ankyrin B [55] and SK1 [56], and PP2A-B56 33 dephosphorylates ChK2 [57]. Thus, the functions of the B56 family members appear to be quite redundant, and it seems likely that the central regulatory mechanism of ERK activation remains to be fully defined.

In this work, we aimed to investigate which subunits of the B56 family are directly involved in ERK activation leading to cell migration. To address this question, we carried out costimulation experiments with EGF and collagen, using Calul lung carcinoma cells and mouse Swiss 3T3 fibroblasts. We found that ERK in nuclei is dephosphorylated only by PP2A-B56 $\gamma 1$. Furthermore, we found two temporally distinct kinetic curves involving PP2AB56 $\gamma 1$; initial loss of activity following stimulation, then sustained low-level activation caused by prompt synthesis of IER3. Our results indicate that the fidelity of the strength and duration of the nuclear ERK activation associated with cell migration is maintained by dynamic regulation mediated by PP2A-B56 $\gamma 1$.

\section{Materials and Methods}

\section{Cells}

Calul lung squamous cell carcinoma line [58] was kindly provided by Dr Takashi Takahashi (Aichi Cancer Institute, Japan), but is also available through American Type Culture Collection. OSC19 oral squamous cell carcinoma line [59] was kindly provided by Dr Yokoi (Sapporo Medical University, Japan). Mouse Swiss 3T3 fibroblasts [59] and a variety of human squamous cell carcinoma lines including HSC3 oral cell carcinoma [60], EBC1 lung carcinoma, LK2 lung carcinoma and A431 esophageal carcinoma [16] were obtained from Japanese Collection of Research Bioresources (Osaka, Japan). The cells of subconfluent cultures, maintained in MEM containing 10\% fetal bovine serum, were harvested with trypsin, and then the trypsin was inactivated with soybean trypsin inhibitor (Sigma, St Louis, MO, USA). The cells were washed with serum-free MEM containing $0.5 \%$ heat-denatured bovine serum albumin (Sigma) and were used for experiments.

\section{Migration Assay}

Cell migration assay was performed in 24-well Transwell chambers containing a polycarbonate membrane with a pore size of $8 \mu \mathrm{m}$ (Corning, Acton, MA, USA) [61]. The undersurface of the membrane was coated with $10 \mu \mathrm{g} / \mathrm{ml}$ type I collagen solution in PBS. Aliquots of 50,000 cells were treated with or without EGF. Cells were treated with PD98059 or cycloheximide for $30 \mathrm{~min}$ prior to EGF stimulation, when necessary. The cells were loaded onto membranes in quadruplicate, and incubated in a $\mathrm{CO}_{2}$ incubator at $37^{\circ} \mathrm{C}$. The cells that migrated on the collagen-coated surface were stained with $2 \%$ crystal violet. The membranes were washed with water, the dye was eluted with $10 \%$ acetic acid, and the optical density of the eluate at $620 \mathrm{~nm}$ was measured. When the number of migrated cells was too small for colorimetric assay, the cells were counted directly under a microscope.

\section{Plasmids}

pCEP plasmids containing B56 $\alpha 1$, B56 $\beta 1$ or B56 $\gamma 1$ cDNA with a 4HA tag (pCEP4HAB56 $\alpha 1$, pCEP4HAB56 $\beta 1$, pCEP4HAB56 $\gamma 1$ ) were provided by Dr David Virshup [62]. Mouse B56 $\gamma 1$ containing vector (pCX4bsr-B56 $\gamma 1$ ) was provided by Dr Ito [63].

\section{DNA Transfection}

The vectors containing B56 were transfected into cells using Lipofectamine 2000 (Invitrogen). pCEP4HAB56 $\alpha 1$, pCE$\mathrm{P} 4 \mathrm{HAB} 56 \beta 1$ and pCEP4HAB56 $\gamma 1$ plasmids were used to transfect Calul cells and pCX4bsr-B56 $\gamma 1$ to transfect mouse Swiss 3T3 cells. The transfected cells were selected with hygromycin or blasticidin for 1 month and stable cell lines were established. The pCEP4HAB56 $\beta 1$ and pCEP4HAB56 $\gamma 1$ plasmids were also used to transiently transfect Calul cells in conjunction with Lipofectamine 2000, and the transfected cells were used for experiments 24 hour later.

\section{RNAi}

To knock down a gene, double-stranded short interference RNA (d-siRNA) was generated using a Block-iT RNAi TOPO Transcription Kit and a Block-iT Dicer RNAi Kit (Invitrogen). A sequence covering IER3 cDNA (470 bp) was amplified by RTPCR using a set of primers. The resultant PCR product was joined to a linker containing a T7 RNA polymerase-recognizing sequence. From the linked sequence a sense template and an antisense template were amplified with the same set of primers and T7 polymerase specific primer. Each DNA template was converted to single-stranded RNA using T7 RNA polymerase. Sense RNA and antisense RNA were annealed to generate doublestranded RNA. The double-stranded RNA was treated with dicer. The resultant 20-23 bp d-siRNA was transfected into Calul cells with Lipofectamine 2000. Gene-specific mRNA expression was measured by a real-time PCR system (ABI PRISM 7000 or Viia7, Applied Biosystems, Foster City, CA, USA), and the specificity and efficiency of knockdown were calculated. For mock RNAi an intron sequence of $\beta 5$ integrin gene [64], which is unrelated to the genes examined in the present study, was used. 

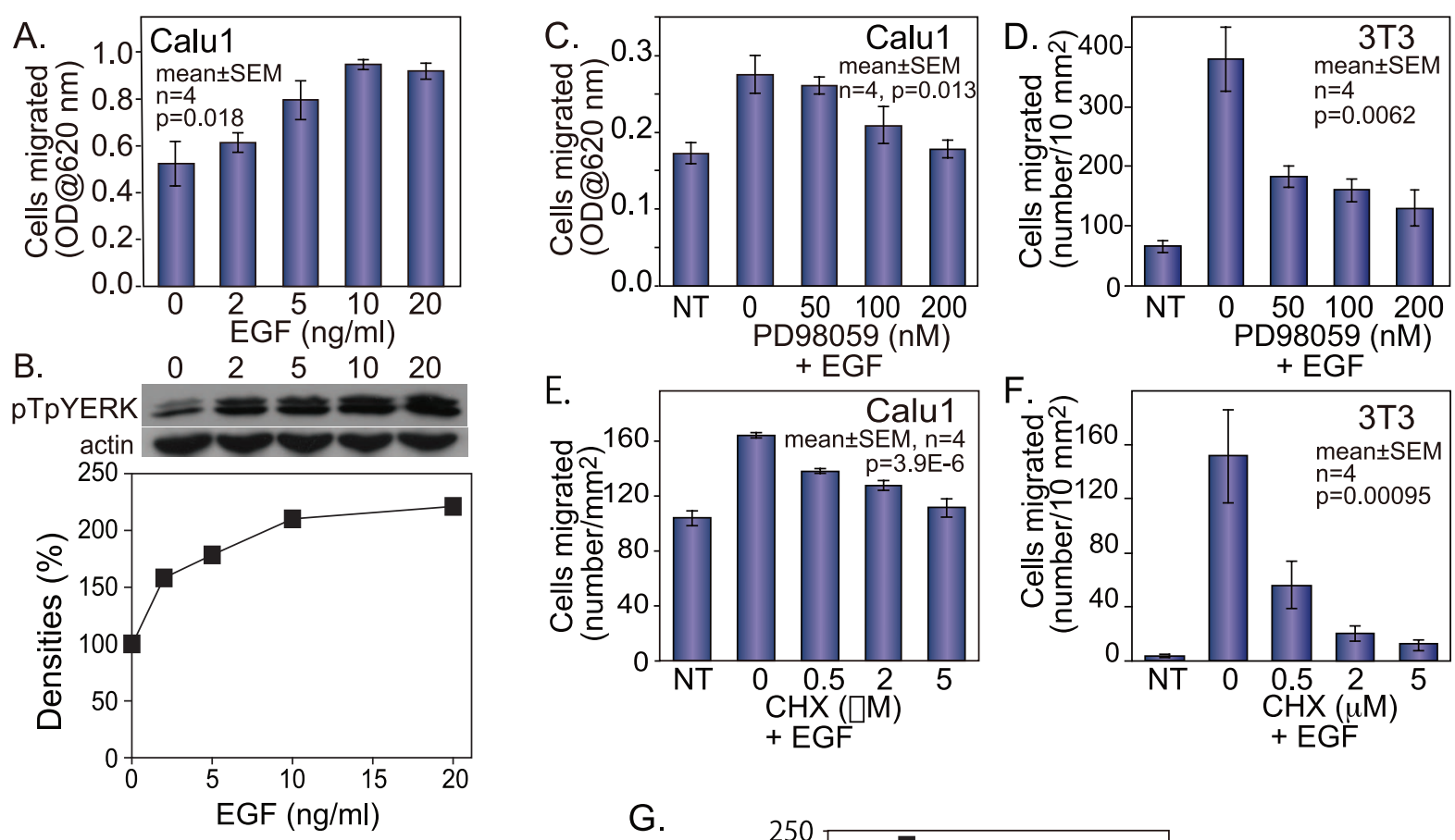

G.
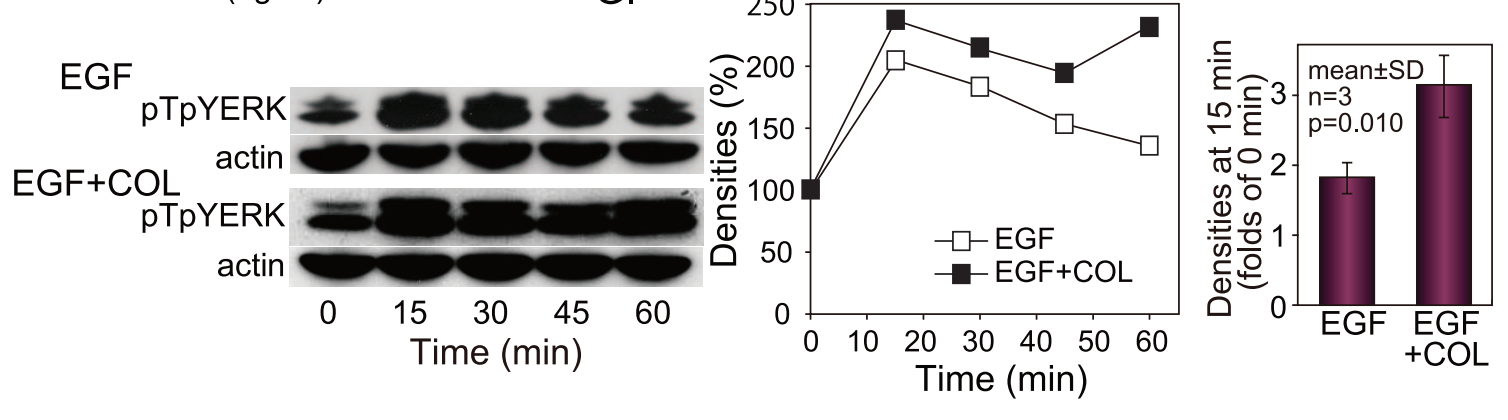

Figure 1. EGF- and collagen-stimulated cell migration and ERK phosphorylation. ( $A$, $C-F)$ Migration assay on collagen using Calu1 carcinoma cells $(A, C, E)$ or Swiss $3 T 3$ fibroblasts $(D, F)$. The cells were allowed to migrate for 5 hours (C, E) or overnight $(A, D, F)$. (A) The dosedependent effect of EGF on Calu1 cell migration. (B) The dose-dependent effect of EGF on threonine- and tyrosine-phosphorylation of ERK1/2 ( $p$ TpYERK) in Calu1 cells. The densities of the bands were measured and plotted on the line chart. (C, D) The effect of PD98059 on EGF-induced cell migration. (E, F) The effect of cycloheximide (CHX) on EGF-induced migration. (G) Kinetics of pTpYERK. Calu1 cells were treated with 10 ng/ml EGF, and the cells were kept in suspension (EGF) or loaded on collagen-coated plates (EGF+COL). The densities of the bands were measured and plotted on the line charts. The levels at $0 \mathrm{~min}$ and $15 \mathrm{~min}$ were determined by densitometric analysis of samples run in the same gel. One way analysis of variance $(A, C, D, E, F)$ or Student's t-test $(G)$ was used for statistical analysis.

doi:10.1371/journal.pone.0063729.g001

\section{Western Blotting}

Cells were lysed with SDS sample buffer $(625 \mathrm{mM}$ Tris-HCl buffer, pH 6.8, 2\% SDS, 10\% glycerol, $01 \%$ bromophenol blue) with or without $6 \%$ mercaptoethanol. Samples were subjected to $10-13 \%$ SDS-PAGE. The samples run in the gel were transferred onto polyvinylidene fluoride membranes (Amersham Hybond-P, GE Healthcare, Buckinghamshire, UK), and reacted with antiphospho-ERK1/2 (Thr $\left.{ }^{202} / \mathrm{Tyr}^{204}\right)$ antibodies (Cell Signaling Technology, Danvers, MA), anti-phospho-ERK1/2 (Tyr $\left.{ }^{204}\right)$ antibodies (Santa Cruz Biotechnology, Santa Cruz, CA, USA), antiPP2A-C $\alpha / \beta$ antibodies (Santa Cruz Biotechnology), anti-actin antibodies (Sigma), anti-phospho-MEK $\left(\mathrm{Ser}^{218} / \mathrm{Se}^{\mathrm{r} 222}\right)$, antiIER3 antibodies (Abnova, Walnut, CA, USA), or anti-HA antibodies (Roche, Manheim, Germany). Then, peroxidaselabeled anti-rabbit IgG antibodies (Cell Signaling Technology), peroxidase-labeled anti-rat antibodies (Cell Signaling Technology) or peroxidase-labeled anti-goat IgG antibodies (Santa Cruz Biotechnology) were applied. Visualisation was performed using a chemiluminescence system (ECL Western Blotting Detection
Reagents, Amersham Biosciences, Buckinghamshire, UK). To compare protein levels, the lysates were run in a single polyacrylamide gel and band densities were determined by densitometric analysis.

\section{Dot Blotting}

Quantification of IER3 protein was examined by dot blot analysis. Cells were lysed with SDS sample buffer or lysis buffer. Samples of equal volume were applied in triplicate, dried and crosslinked to PVDF membrane by an ultraviolet crosslinker (UV stratalinker 1800, Stratagene, La Jolla, CA, USA). The membrane was reacted with anti-IER3 antibodies and peroxidase-labelled anti-rabbit IgG antibodies. Chemiluminescence reaction was performed using ECL Western Blotting Detection Reagent and evaluated with an image analyzer (Lumi-Imager F1, Roche Diagnostics). Protein concentrations in the samples were measured using RC-DC Protein Assay. A sample with maximum protein concentration was serially diluted to prepare a standard curve so that relative amounts could be obtained. The amounts of IER3 


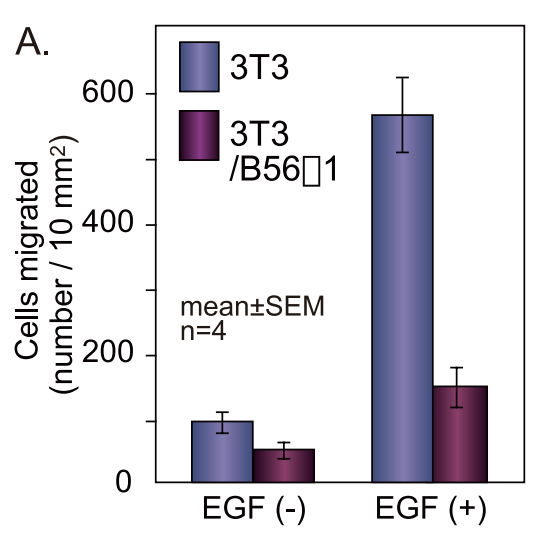

B. $\quad$ No EGF EGF $30 \mathrm{~min}$

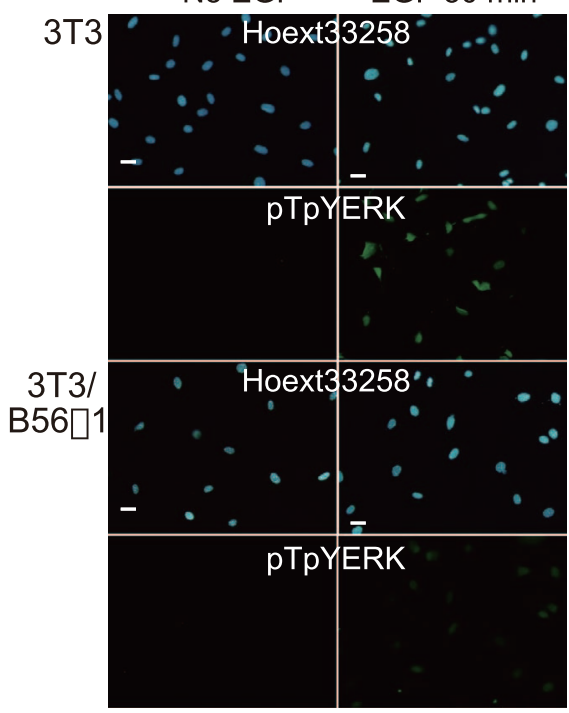

C.

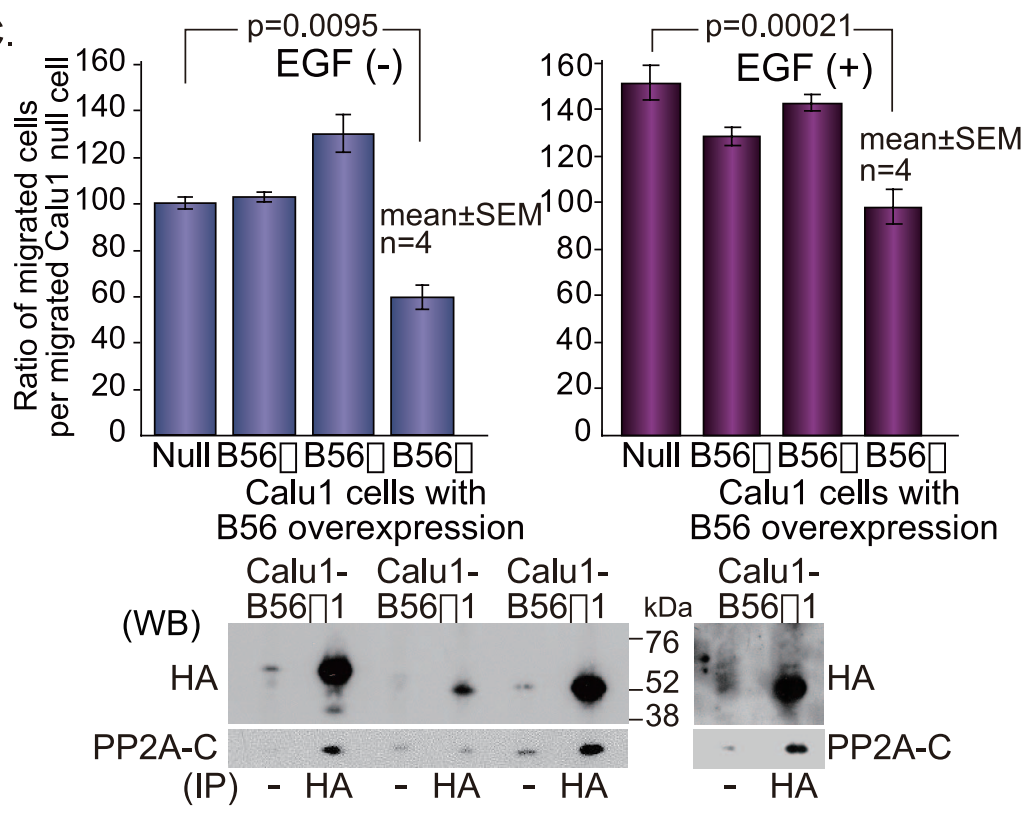

D.
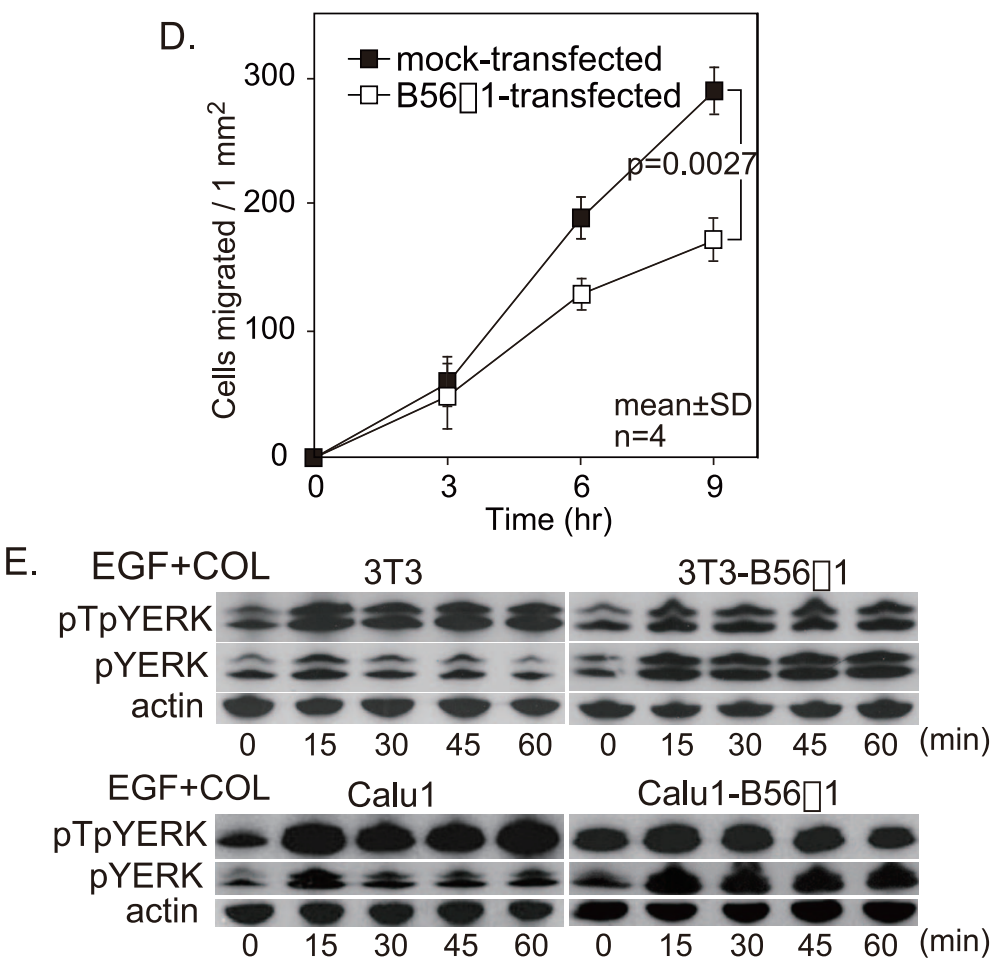

Figure 2. B56 $\gamma 1$ overexpression inhibits both cell migration and ERK phosphorylation. (A) The effect of B56 1 overexpression on migration of 3T3 cells. (B) The effect of B56 $\gamma 1$ overexpression on ERK phosphorylation in 3T3 cells. Bars, $10 \mu \mathrm{m}$. (C) The effects of B56 overexpression on migration using permanently transfected Calu1 cells. Migration of Calu1 cells, which were permanently transfected with pCEPB56 $\alpha 1$, pCEPB56 31 or pCEPB56 $\gamma 1$, was compared with that of untransfected Calu1 cells (null). B56 protein in each cell line $\left(2 \times 10^{6}\right.$ cells) is shown by western blotting with anti-HA antibodies following to immunoprecipitation with anti-HA antibodies, and coprecipitated $\mathrm{C}$ subunit is shown by western blotting with antiPP2A-C subunit antibodies. To detect binding of $C$ subunit to B56 $\beta 1$ protein in B56 $\beta 1$-transfected Calu1 cells, $6 \times 10^{6}$ cells were used and the blot is shown in the right. (D) The effects of B56 overexpression on migration using transiently transfected Calu1 cells. Migration of Calu1 cells, which were transiently transfected with pCEPB56 1 , was compared with that of Calu1 cells, which were transiently transfected with empty plasmids. (E) The effect of B56 11 overexpression on kinetics of PTPYERK and pYERK after costimulation in Calu1 cells. Scheffe's multiple comparison after one way analysis of variance (C) or two way analysis of variance (D) was used for statistical analysis. doi:10.1371/journal.pone.0063729.g002

determined from the standard curve were calibrated with the protein concentrations of the samples.

\section{Pulldown Assay}

HA-B56 transfected Calul cells were dissolved in lysis buffer (50 mM Tris-HCl buffer, $\mathrm{pH}$ 7.4/150 mM NaCl/1\% NP-40/ 


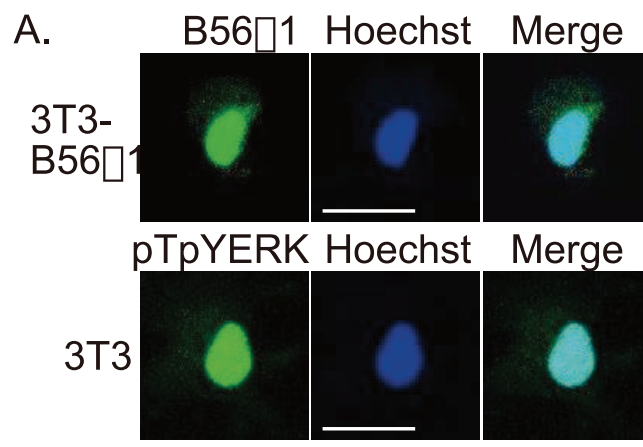

\section{Calu1-B56ロ1}
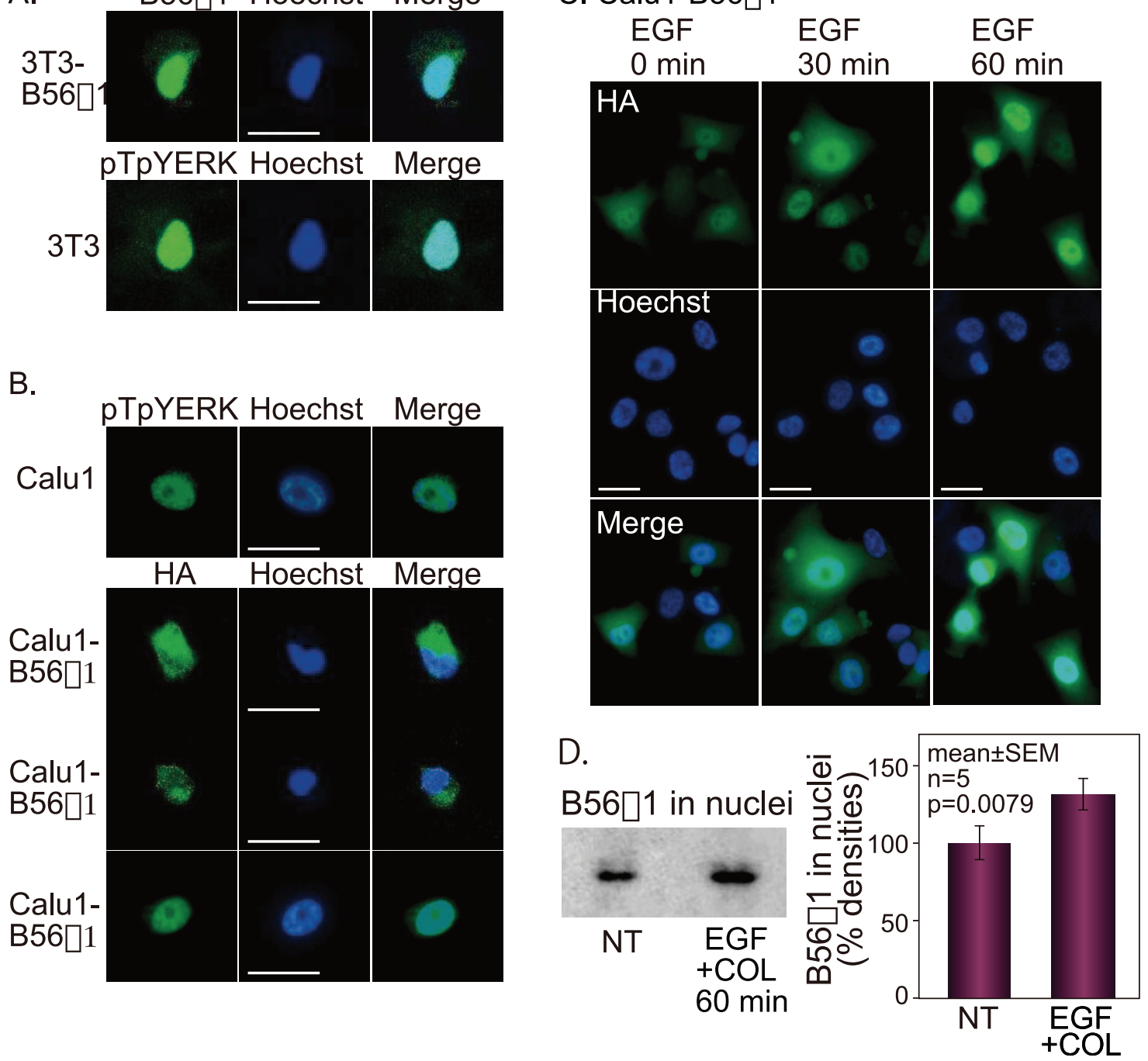

Figure 3. Nuclear localization of pTpYERK and B56 $\gamma$ 1. (A) Immunolocalization of B56 $\gamma 1$ in 3T3-B56 $\gamma 1$ cells and pTpYERK in $3 T 3$ cells stimulated with EGF on collagen was analyzed using a confocal laser scanning microscope. To detect mouse B56 $\gamma 1$ protein anti-mouse B56 11 antibodies were

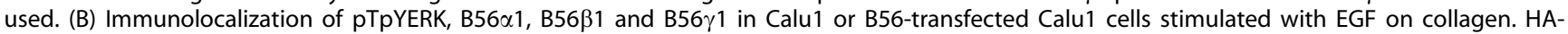
tagged B56 proteins were detected using anti-HA antibodies. Nuclear or perinuclear immunolocalization was detected by a confocal laser scanning

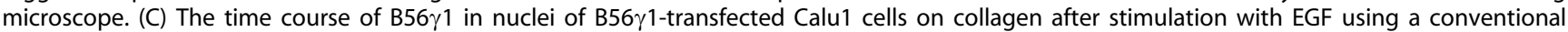
fluorescence photomicroscope. Nuclei were stained with Hoechst 33258. Bars, $10 \mu \mathrm{m}$. (D) B56 11 protein in nuclei. EGF was added to suspension of B56 $\gamma 1$-transfected Calu1 cells, and the cells were immediately loaded on a collagen-coated plastic plate. Extracted nuclear protein from the cells with no treatment (NT) and both with EGF and collagen (EGF+COL) was used for western blot analysis using anti-HA antibodies. Paired t-test was used for statistical analysis.

doi:10.1371/journal.pone.0063729.g003

$0.25 \%$ sodium deoxycholate/ $1 \mathrm{mM}$ phenylmethylsulfonyl fluoride/ $1 \mu \mathrm{g} / \mathrm{ml}$ leupeptin $/ 2 \mu \mathrm{g} / \mathrm{ml}$ aprotinin/ $10 \mathrm{mM}$ mercaptoethanol). Proteins in the cell lysates were immunoprecipitated with protein G Sepharose (Amersham Biosciences) and specific antibodies. The precipitate was washed and SDS-sample buffer with or without mercaptoethanol was added. Protein of interest in the immune complex was detected by western blotting. As a negative control, Protein G Sepharose was suspended in cell lysate without the specific antibodies.

\section{In vitro Immune Complex Phosphatase Assay}

To quantify PP2A-B56 $\gamma 1$ phosphatase activity, a fluorometric phosphatase assay [65] was used. Calu1-B56 71 cells, which were stimulated with EGF and loaded onto a collagen-coated plate for a suitable period, were lysed with lysis buffer. The protein concentration in the supernatant was measured, and samples containing equal amounts of protein were used. B56 $\gamma 1$ was immunoprecipitated from the lysate with anti-HA antibodies and protein G Sepharose. The immobilized B56 $\gamma 1$ complex was reacted with 4-methylumbelliferyl phosphate (Wako Pure Chemical Industries, Osaka, Japan) in phosphatase buffer (50 mM Tris$\mathrm{HCl}, \mathrm{pH} 7.5 / 1 \mathrm{mM} \mathrm{MgCl} / 1 \mathrm{mM}$ EGTA), and the fluorescence intensity of the released 4-methylumbelliferone was measured with an emission wavelength of $450 \mathrm{~nm}$ and excitation wavelength of $360 \mathrm{~nm}$ using a microplate fluorometer (FluoDia T70, Photon Technology International, Birmingham, NJ, USA).

To qualify phosphatase activity of PP2A-B56 on pTpYERK, B56 $\alpha 1, \mathrm{~B} 56 \beta 1$ and B56 $\gamma 1$ were immunoprecipitated with anti-HA antibodies, and then immobilized on Protein G Sepharose. Crude cell lysate containing pTpYERK after stimulation with EGF was 


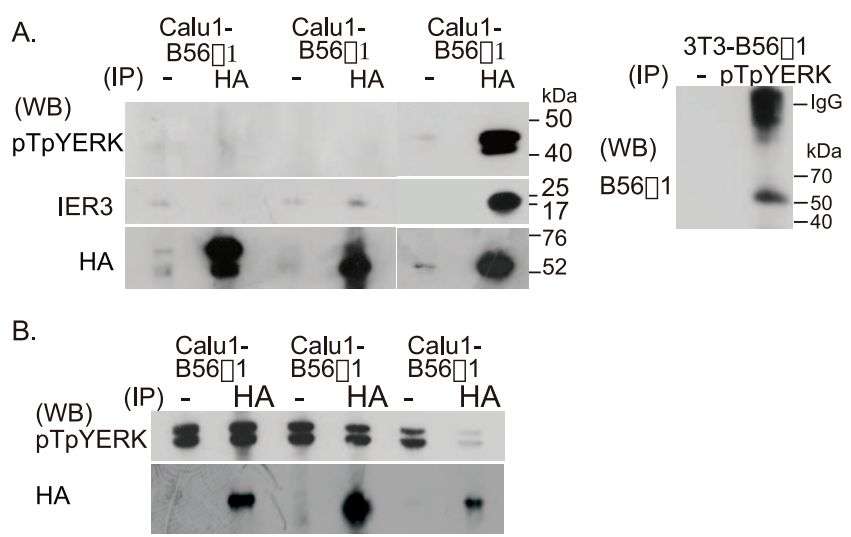

Figure 4. PP2A-B56 $\gamma 1$ binds to and dephosphorylates pTPYERK. (A) Pull down assay. HA-tagged B56 protein in B56transfected Calu1 cells was immunoprecipitated with anti-HA antibodies. PTPYERK, IER3 and B56s in the immune complex were detected by western blotting. Similarly, the complex immunoprecipitated from 3T3B56 $\gamma 1$ cells with rabbit anti-pTpYERK antibodies was run in polyacrylamide gel under non-reducing conditions and B56 11 was detected by western blotting using rabbit anti-mouse B56 11 antibodies and HRPlabeled anti-rabbit IgG antibodies. (B) Immune complex phosphatase assay. Immobilized PP2A trimer co-immunoprecipitated with anti-HA antibodies on protein G-Sepharose beads was used as an enzyme and pTpYERK-rich cell lysate of Calu1 cells stimulated with EGF was used as a substrate. Beads suspensions were incubated for $30 \mathrm{~min}$ in the crude substrate solution. PTPYERK in the reacted lysate was detected by western blotting. Immunoprecipitated enzyme was quantitated by western blotting using rat anti-HA antibodies. doi:10.1371/journal.pone.0063729.g004

used as a substrate. Immobilized B56 immune complexes were suspended in the crude cell lysate. As a negative control, Protein G Sepharose without immune complex was reacted with the crude cell lysate.

\section{Protein Assay}

Since cells placed on a collagen-coated plate for less than $5 \mathrm{~min}$ were hard to fully collect, protein concentrations were measured using a protein assay kit (RG-DG Protein Assay, Bio-Rad, Hercules, CA, USA) and samples with equal protein amounts were used for western blotting, dot blotting and phosphatase assay.

\section{Extraction of Nuclear Protein}

Cytoplasmic extraction buffer $(120 \mathrm{mM} \mathrm{KCl} / 20 \mathrm{mM}$ Tris-HCl buffer, pH 7.9/2 mM EDTA/2 mM dithiothreitol/1 mM phenylmethylsulfonyl fluoride/ $1 \mu \mathrm{g} / \mathrm{ml}$ leupeptin $/ 2 \mu \mathrm{g} / \mathrm{ml}$ aprotinin) with NP-40 was added to cells. Preipitated nuclei after centrifugation were washed with cytoplasmic extraction buffer. Then, nuclear extraction buffer $(40 \mathrm{mM}$ Tris-HCl buffer, $\mathrm{pH} 7.9$ / $800 \mathrm{mM} \mathrm{NaCl}, 30 \mathrm{mM}$ EDTA/50\% glycerol) was added, vortexed and centrifuged. The resultant supernatant was used for analysis of nuclear protein.

\section{Immunofluorescence}

Glass slides with 8 plastic chambers (Lab-Tek II Chamber Slides, Nunc, Rochester, NY) were coated with $10 \mu \mathrm{g} / \mathrm{ml}$ type I collagen solution. Aliquots of 5,000 cells were loaded into each well and the slide was placed in a $\mathrm{CO}_{2}$ incubator for $30 \mathrm{~min}$, and then the cells were stimulated with EGF or not stimulated. The cells were fixed with $3 \%$ paraformaldehyde, permeabilized with $0.01 \%$ Triton X-100, blocked with 2\% BSA, and then incubated with anti-HA antibodies, anti-phospho-ERK1/2 $\left(\mathrm{Thr}^{202} \mathrm{Tyr}^{204}\right)$
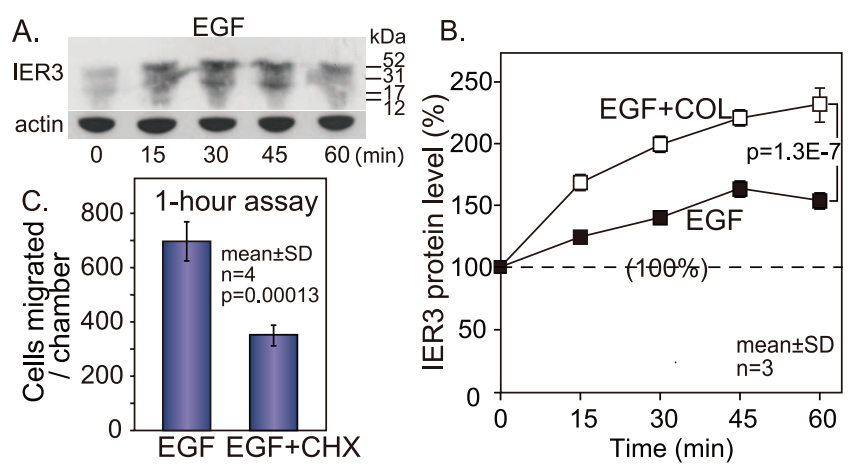

Figure 5. IER3 protein is promptly synthesized in response to EGF and adhesion. (A) Kinetics of IER3 protein expression evaluated by western blotting. (B) Kinetics of IER3 protein expression measured by dot blot analysis. (C) The effect of cycloheximide on early migration of Calu1 cells. Two way analysis of variance was used for statistical analysis.

doi:10.1371/journal.pone.0063729.g005

antibodies, anti-mouse B56ZZZ1 antibodies (provided by $\mathrm{Dr}$ Nojima), or anti-actin antibodies. As secondary antibodies, Alexa Fluor 488-labeled anti-rabbit antibodies, Alexa Fluor 488-labeled anti-rat IgG antibodies, or Alexa Fluor 594-labeled anti-rabbit antibodies (Molecular Probes, Eugene, OR) were used. Immunofluorescence was observed under a conventional fluorescence microscope (BX50, Olympus, Tokyo, Japan) or a confocal laser scanning microscope (LSM510, Carl Zeiss, Munich, Germany). Nucei were counterstained with Hoechst33258 (Dojindo, Kumamoto, Japan).

\section{Statistics}

Student's t-test was used for comparison of the averages between two groups. For multiple comparisons, one- or two-way analysis of variance was used and for the subsequent comparison between two groups among them, Scheffe's multiple comparison was used.

\section{Results}

\section{Cell Migration Requires Intense and Sustained Activation} of ERK

Migratory activities of various cultured cell lines on collagen were examined using a 5-hour or overnight migration assay. Both Calul cells of human lung carcinoma origin and Swiss 3T3 cells of mouse fetal fibroblast origin migrated in response to EGF in this assay system (Figure 1A, F). We further examined a variety of squamous carcinoma cells, including A431 esophageal carcinoma, EBC1 lung carcinoma, LK2 lung carcinoma, OSC19 oral carcinoma and HSC3 oral carcinoma cells, and found that all of them migrated similarly in response to EGF in this assay. The level of pTpYERK in a suspension of Calul cells, as estimated by western blotting, was also increased dose-dependently by EGF (Figure 1B). The minimal concentration of EGF that induced both the maximum cell migration and the highest phosphorylation of ERK was $10 \mathrm{ng} / \mathrm{ml}$ (Figure 1A, B). Therefore, $10 \mathrm{ng} / \mathrm{ml} \mathrm{EGF}$ was used for all subsequent experiments in the present study.

The EGF-induced migration of Calul cells and 3T3 cells was inhibited by the MEK inhibitor PD98059 (Figure 1C, D), indicating that the EGF-induced migration on collagen is mediated by ERK. The protein synthesis inhibitor cycloheximide also inhibited the EGF-induced migration of Calul cells (Figure 1E) and 3T3 cells (Figure 1F) in a dose-dependent 


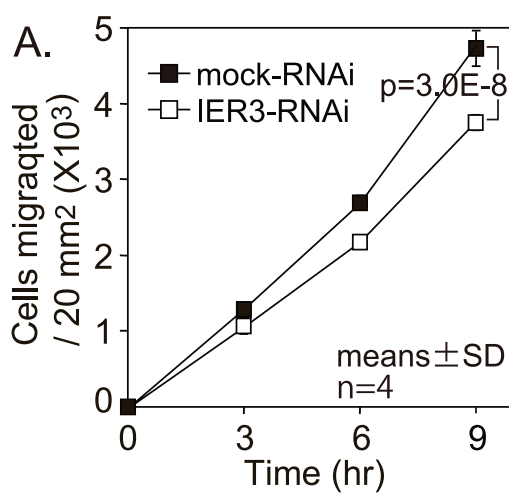

D.

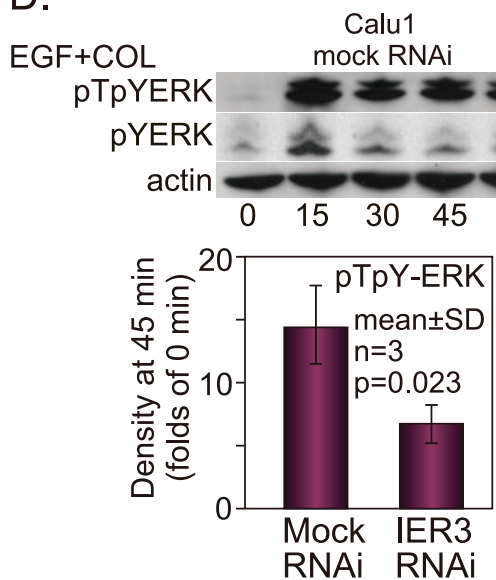

B. 20

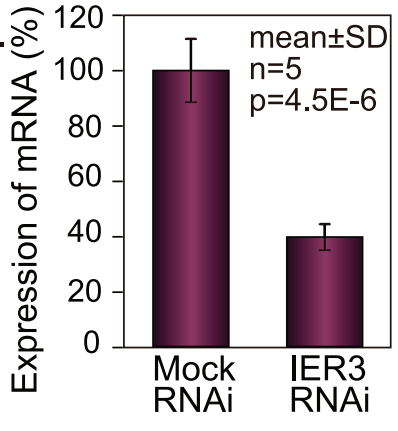

C.

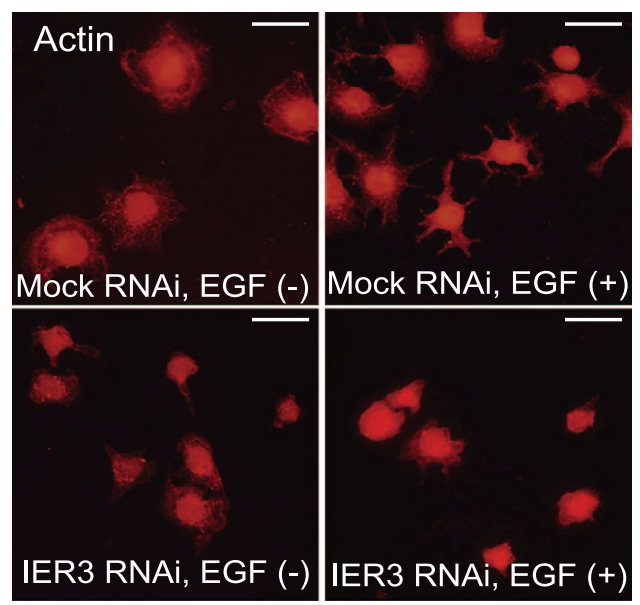

Calu1 IER3 RNAi
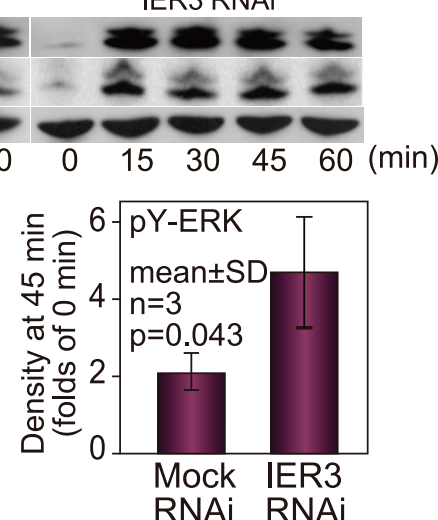

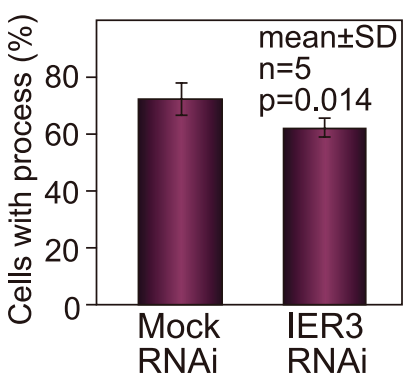

Figure 6. IER3 knockdown decreases cell migration and increase ERK dephosphorylation. (A) The effect of IER3 RNAi on migration of Calu1 cells. (B) The effect of RNAi on IER3 mRNA expression. (C) The effect of IER3 RNAi on the structure of actin cytoskeleton. The numbers of cells with cytoplasmic processes were counted under a fluorescence microscope. (D) The effect of IER3 RNAi on kinetics of pYERK and pTpYERK. Bars, $10 \mu \mathrm{m}$. Two way analysis of variance (A) or Student's t-test (B, C, D) was used for statistical analysis. doi:10.1371/journal.pone.0063729.g006

manner, indicating that this migration requires de novo protein synthesis.

When EGF was added to a suspension of Calul cells (EGF-only group), the level of pTpYERK was increased, reaching the maximum 15 min later, and then the ERK phosphorylation level continuously decreased until $60 \mathrm{~min}$ (Figure lG). When the cells were stimulated with EGF and then immediately loaded onto collagen-coated dishes (EGF+COL), the level of pTpYERK was also increased at $15 \mathrm{~min}$, but this level of phosphorylation then persisted until 60 minutes (Figure 1G). The levels of pTpYERK phosphorylation at $0 \mathrm{~min}$ and $15 \mathrm{~min}$ under these two different conditions were determined by densitometric analysis of samples run in the same gel. This analysis showed that the level of pTpYERK at 15 min under the EGF+COL condition was significantly higher than that under the EGF-only condition. Thus, both intense and sustained activation of ERK induced by $\mathrm{EGF}+\mathrm{COL}$ stimulation are required for cell migration.

\section{Overexpression of B56 11 Reduces Both EGF-induced Cell Migration and Phosphorylation of ERK}

To determine what factors, other than MEK, might induce or maintain the intense and sustained activation of ERK following EGF treatment, we analysed the potential involvement of the B56 family of PP2A heterotrimers. The mouse B56 $\gamma 1$ cDNA-containing plasmid pCX4bsr was transfected into 3T3 cells (3T3-B56 $\gamma 1$ ). The resulting overexpression of B56 $\gamma 1$ led to inhibition of EGFinduced migration of the cells (Figure 2A). The effect of B56 $\gamma 1$ overexpression on ERK phosphorylation was also examined using immunofluorescence assay. 3T3-B56 $\gamma 1$ cells and 3T3 cells were stimulated with EGF and immediately loaded onto collagencoated glass slides, and then ERK phosphorylation was analysed. The immunofluorescence signal of pTpYERK in 3T3-B56 $\gamma 1$ cells after EGF stimulation was weaker than that in 3T3 cells (Figure 2B).

pCEP plasmids containing B56 $\alpha 1$, B56 $\beta 1$ or B56 $\gamma 1$ were permanently transfected into Calul cells (pCalu1-B56 $\alpha 1$, pCalu1B56 31 , pCalu1-B56 $\gamma 1$ ). Since all carcinoma cell lines we examined migrated well even when EGF was not added, we examined the effect of B56 $\gamma 1$ overexpression on migration of Calul cells in the presence and absence of EGF. pCalu1-B56 $\gamma 1$ cells showed significantly less migration on collagen than did Calul cells, both when the cells were stimulated with EGF and when they were not EGF-stimulated (Figure 2G). The pCalulB56 $\alpha 1$ cells and pCalu1-B56 $\beta 1$ cells migrated similarly to Calul cells with or without EGF (Figure 2C). To know if the overexpressed B56 protein forms a complex with $\mathrm{C}$ catalytic subunit, pulldown assay was performed. Coprecipitation of $\mathrm{C}$ subunit with $\mathrm{B} 56 \alpha 1$ and B $56 \gamma 1$ was detected, and that with B56 $\beta 1$ was not detected when cells with the same count were used (Figure 2C). Coprecipitation of $\mathrm{C}$ subunit with B56 31 was detected after the similar protein level of $\mathrm{B} 56 \beta 1$ to those of B56 $\alpha 1$ and B56 $\gamma 1$ was used (Figure 2C).

We also examined the migratory activities of Calul cells transiently transfected with pCEP plasmids containing B56 11 

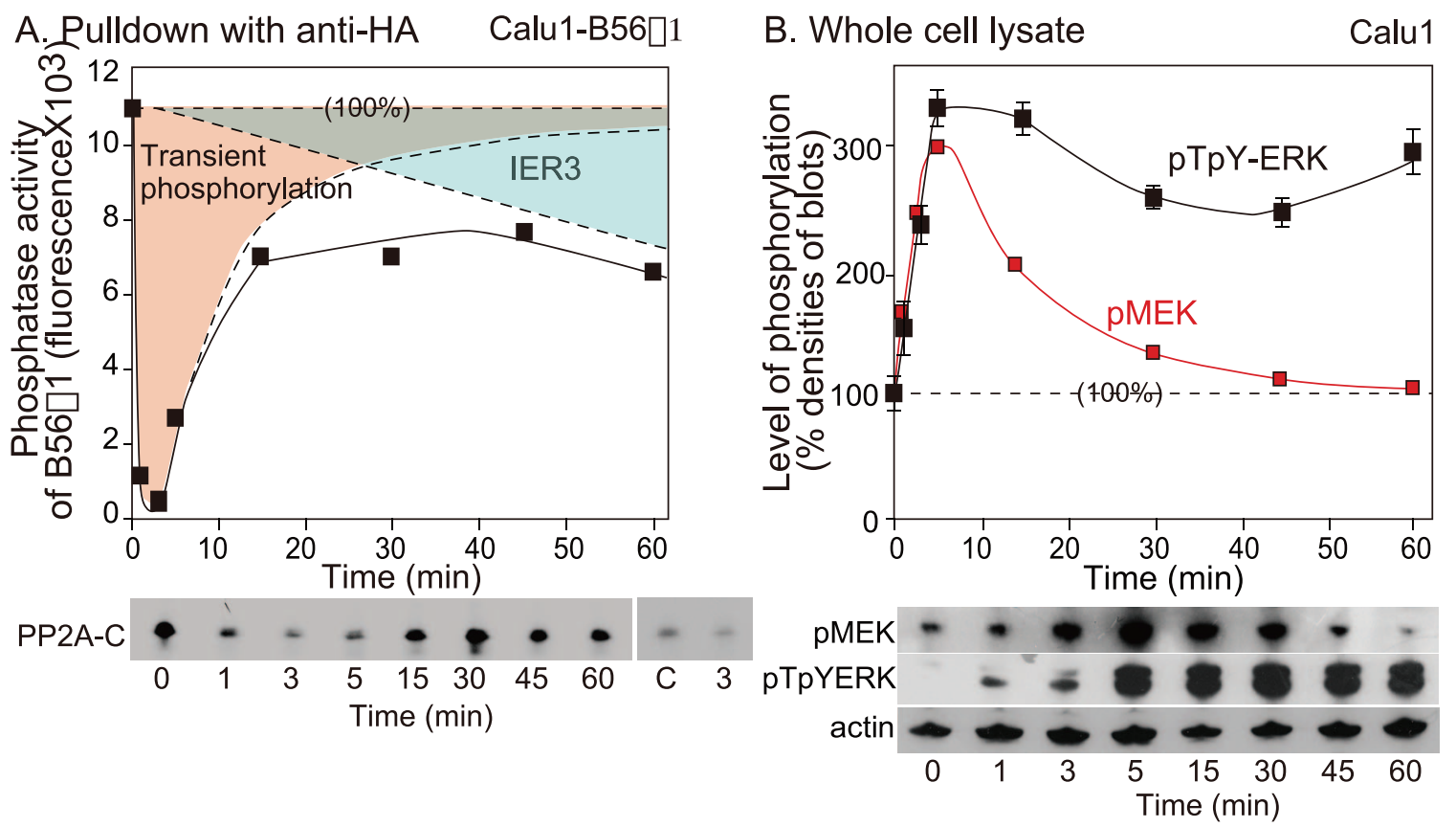

Figure 7. The strength and duration of ERK activation is determined by MEK and PP2A-B56 $\gamma 1$ activities. (A) The activity of PP2A-B56 $\gamma 1$ phosphatase measured by immune complex fluorometric phosphatase assay using 4-methylumbelliferyl phosphate as a substrate. The closed squares indicate the measured phosphatase activity. Two areas demarcated by dotted lines ("transient phosphorylation" and "IER3") were deduced from the effect of two distinct factors, i.e., the rapid inactivation of phosphatase activity (probably due to phosphorylation of the C subunit of PP2A) and the later PP2A inactivation reaction by IER3. C subunits of PP2A in the immune complex were detected by western blotting using anti-C subunit antibodies. Since faint blot at 3 min shows non-specific binding to Sepharose beads, densities of non-immune controls (C) and of 3 min are being compared. (B) The kinetics of ERK and MEK activities in Calu1 cells were examined by western blotting. The plot was constructed using data from 3 ( 0 to $15 \mathrm{~min})$ or $9(0,15$ to $60 \mathrm{~min})$ repeated experiments.

doi:10.1371/journal.pone.0063729.g007

(tCalu-mock). The migratory activity of the transfected cells was compared to that of Calul cells that had been transiently transfected with empty pCEP plasmids (tCalul-mock). The assay showed that the migration of tCalul-B56 $\gamma 1$ cells was significantly lower than that of tCalul-mock cells (Figure 2D).

Western blotting indicated that the level of pTpYERK in 3T3B56 $\gamma 1$ cells after EGF+COL stimulation was slightly lower than that in 3T3 cells (Figure 2E). Analysis of the level of ERK that was phosphorylated only at the tyrosine residue and not at the threonine residue (pYERK), which was assessed using a specific antibody, yielded interesting results. The intensity of the pYERK band increased at $15 \mathrm{~min}$ after costimulation with EGF+COL, but then decreased to the original level within $30 \mathrm{~min}$ in 3T3 cells. The change was more marked after costimulation of 3T3-B56 $\gamma 1$ cells than after co-stimulation of 3T3 cells (Figure 2E). Similar results were obtained when the same experiment was performed using Calul cells (Figure 2E). All of these results suggested that pTpYERK is dephosphorylated (inactivated/inhibited) by PP2AB56 $\gamma 1$, a serine/threonine phosphatase that dephosphorylates phospho-threonine in the TEY motif.

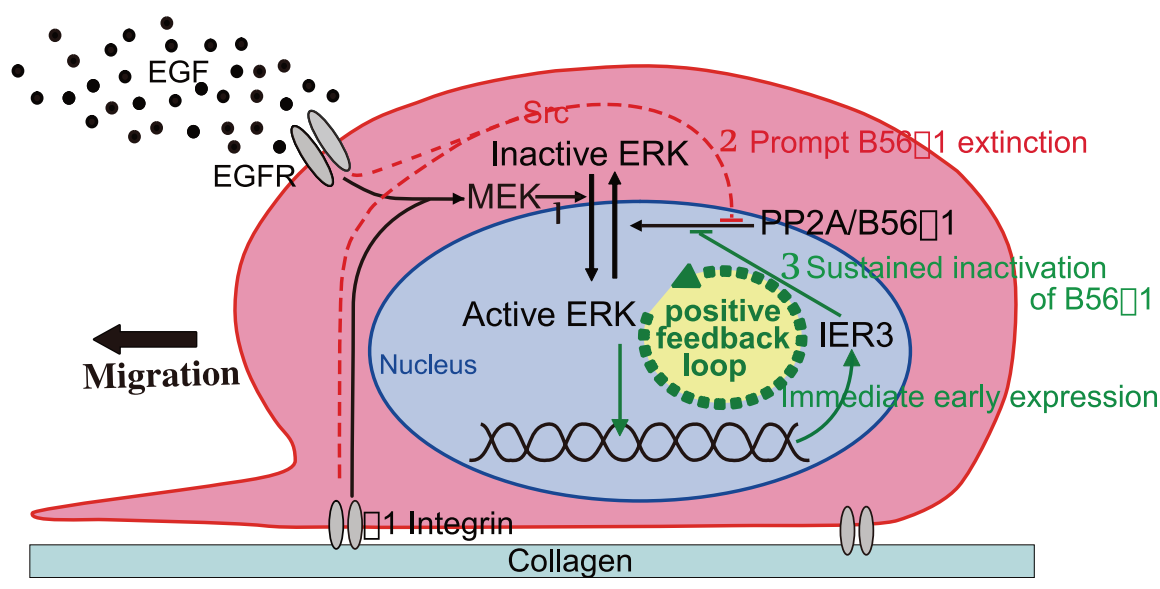

Figure 8. Schematic illustration of proposed mechanisms of ERK-mediated cell migration regulated by PP2A-B56 $\gamma 1$. The numbers 1,2 and 3 indicate the main signalling pathways that regulate ERK activation within the first 60 min following stimulation. doi:10.1371/journal.pone.0063729.g008 


\section{PP2A-B56 1 Dephosphorylates ERK in Nuclei}

Possible colocalization of B56 proteins and pTpYERK within cells was examined by immunofluorescence. All of the cell lines analyzed were treated with EGF and placed on collagen for $30 \mathrm{~min}$, followed by immunofluorescence analysis of protein localization. Using a conventional immunofluorescence micro-

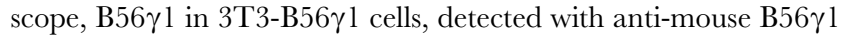
antibodies and fluorescence-labelled secondary antibodies, appeared to be localized in both the nuclei and the perinuclear area. Since non-specific fluorescence in the perinuclear area can be an issue in conventional fluorescence microscopy, a confocal laser scanning microscope was next used to examine fluorescence in thin tissue slices. In serial $1-\mu \mathrm{m}$-thick sections, B56 $\gamma 1$ in 3T3B56 1 cells and pTpYERK in 3T3 cells were clearly localized in nuclei, and no fluorescence signal was observed in the perinuclear region (Figure 3A). pTpYERK immunofluorescence was also detected in the nuclei of Calul cells using a confocal laser scanning microscope (Figure 3A). The subcellular localization of B56 $\alpha 1$, B56 $\beta 1$, and B56 $\gamma 1$ was further examined by immunofluorescence analysis of permanently B56-transfected Calul cells, using anti$\mathrm{HA}$ antibodies. Both $\mathrm{B} 56 \alpha 1$ and $\mathrm{B} 56 \beta 1$ were localized in the perinuclear area (Figure 3B). B56 $\gamma 1$ was localized only in nuclei and was not seen in any other subcellular localization (Figure 3B).

Immunolocalization of $\mathrm{B} 56 \gamma 1$ was also examined in the presence and the absence of EGF in pCalul-B56 $\gamma 1$ cells on collagen. Immunofluorescence of B56 $\gamma 1$ was not clearly observed when the cells were not stimulated with EGF, but was detected in the nuclei at 30 to $60 \mathrm{~min}$ after EGF stimulation (Figure 3C). Quantitatively, western blot analysis in nuclear protein extracted from Calu 1-B56 $\gamma 1$ cells using anti-HA antibodies showed increase in B56 $\gamma 1$ protein in nuclei after cells were treated with EGF and loaded on collagen (Fig. 3D).

HA-B56 proteins were each immunoprecipitated with anti-HA antibodies from lysates of permanently B56-transfected Call1 cells, and co-precipitating endogenous pTPYERK was analysed by western blotting using anti-pTpYERK antibodies. This experiment showed that B56 $\alpha 1$ and B56 $\beta 1$ did not bind to pTpYERK, but that B56 $\gamma 1$ did bind to pTpYERK (Figure 4A). B56 $\gamma 1$ protein was found to co-precipitate with pTpYERK (Figure 4A). To determine the ability of PP2A associated with different B56 subunits to dephosphorylate pTpYERK, in vitro immune complex phosphatase assays were performed. PP2A that co-precipitated with HA-tagged B56 proteins from each pCalul-B56 cell line was incubated with pTpYERK-rich cell lysates, i.e., lysates of Calul cells that had been stimulated with EGF for $30 \mathrm{~min}$. The effect of this incubation on pTpYERK phosphorylation was analysed by western blotting. This experiment showed that PP2AB56 1 l dephosphorylated pTpYERK, but that PP2A-B56 $\alpha 1$ and PP2A-B56 $\beta 1$ did not (Figure 4B), although the amounts of the immunoprecipitated B56s varied somewhat (Figure 4B).

\section{IER3 Induces Cell Migration via Sustained Activation of ERK}

It was suggested that immediate early response protein3, IER3 (formerly known as IEX1) induced sustained activation of ERK [66] by inhibiting B56-containing PP2A [39]. Indeed, we found, by using a pulldown assay, that IER3 binds to B56 $\gamma 1$ (Figure 4A). IER 3 was not coprecipitated with $\mathrm{B} 56 \alpha \mathrm{l}$ and $\mathrm{B} 56 \beta 1$ by the pulldown assay (Figure 4A). If IER3 induces sustained activation of ERK for cell migration through interaction with PP2A-B56 $\gamma 1$, the IER3 protein should be fully expressed within $30 \mathrm{~min}$ after costimulation with EGF plus COL. It has been reported that the expression of IER3 mRNA starts within 10 minutes after EGF stimulation [67], but it is not known exactly how long it takes for
IER3 protein expression to begin. We therefore examined the kinetics of IER3 protein expression following stimulation with EGF or EGF+COL. Unglycosylated and glycosylated forms of IER 3 were visualized by western blotting (Figure 5A) and dot blot analysis was used for quantification. We found that, when the cells were stimulated with EGF or EGF+COL, IER3 protein was moderately expressed within $15 \mathrm{~min}$ (Figure 5B), suggesting that the protein expression started within a few minutes of stimulation. The IER 3 protein accumulated more rapidly when the cells were stimulated with EGF+COL than when they were stimulated with EGF alone (Figure 5B). These results led us to re-examine the effect of cycloheximide on EGF-induced migration at an early time point, and we found that cycloheximide inhibited EGFinduced cell migration at 1 hour after EGF administration (Figure 5G).

We next determined the effect of IER3 knockdown on cell migration. RNAi against IER3 inhibited the migration of Calul cells (Figure 6A). The rate of decrease in migration was 20\% at 9hour migration, which was less than the effect of B56 1 overexpression (Figure 2D), and then the inhibitory efficiency of mRNA expression was measured by a real time PCR. The inhibition of the expression of IER 3 mRNA was not complete but 38\% (Figure 6B). When Calul cells or Calul cells transfected with mock d-siRNA were treated with EGF and loaded onto collagencoated glass slides, the cells exhibited cytoplasmic processes (Figure 6C). When Calul cells were transfected with IER3 dsiRNA, generation of these cell processes was inhibited (Figure 6C), indicating that these cells would have low migratory activity [60]. To quantify the difference in the effect between mock RNAi and IER3 RNAi, the numbers of cells with cytoplasmic processes were counted under a fluorescence microscope. There was a significant difference in the percentages of cells positive for cytoplasmic processes (Figure 6B). The effects of IER3 knockdown on ERK phosphorylation were also examined by western blotting using anti-pTpYERK and anti-pYERK antibodies. IER3 knockdown led to enhanced dephosphorylation of pTpYERK, resulting in a change from sustained activation to transient activation of ERK (Figure 6D). In contrast, IER3 knockdown changed the transient increase in pYERK to a sustained increase by enhancing dephosphorylation of pTpYERK at the threonine residue (Figure 6D).

\section{Kinetics of Activities of B56 1 1, ERK and MEK Following EGF/COL Stimulation}

Calu1-B56 $\gamma 1$ cells were stimulated with EGF/COL, and PP2AB56 $\gamma 1$ phosphatase activity between 0 and $60 \mathrm{~min}$, especially during the first $15 \mathrm{~min}$ period, was examined using an immune complex fluorometric assay. Unexpectedly, these data showed that PP2A-B56 1 activity dramatically decreased within $1 \mathrm{~min}$ of stimulation, to the point where no activity could be detected (Figure 7A). However, after a few more minutes, PP2A-B56 $\gamma 1$ activity started to increase, and then it gradually increased over the next $15 \mathrm{~min}$, and was maintained at approximately the same level between $15 \mathrm{~min}$ and $60 \mathrm{~min}$ (Figure 7A). The recovered activity was lower than the initial activity. The kinetics of phosphatase activity over the entire $60 \mathrm{~min}$ after stimulation suggested the existence of two different phases. The earlier phase involves a robust inactivation, and the later phase shows a sustained moderate activation. We next analyzed the presence of the catalytic $\mathrm{C}$ subunit of PP2A in the same HA-precipitated immune complexes by western blotting using anti-Csubunit antibodies. The $\mathrm{C}$ subunit that was initially bound to B56 $\gamma 1$ was not detected in precipitates between 1 to 5 min after treatment but was detected at subsequent time points and its levels were maintained at an 
approximately similar level between $15 \mathrm{~min}$ and $60 \mathrm{~min}$ of stimulation. The time course of the association of the $\mathrm{C}$ subunit of PP2A was coincident with the kinetics of PP2A-B56 $\gamma 1$ phosphatase activities (Fig. 7A).

Sustained inactivation of PP2A-B56 $\gamma 1$ phosphatase activity should correspond with sustained phosphorylation of ERK. We therefore reassessed the kinetics of ERK phosphorylation in the later phase following EGF/COL stimulation. The intensities of the bands of pTpYERK previously obtained by western blotting were plotted (Figure 7B). The plot of the kinetics of pTpYERK phosphorylation was the reciprocal of that of PP2A-B56 $\gamma 1$ activity (Figure 7A, B). We also examined the kinetics of pTpYERK phosphorylation in the early phase following EGF/COL treatment (Figure 7B). The highest peak of pTpYERK phosphorylation was at $5 \mathrm{~min}$, which was $4 \mathrm{~min}$ after the initiation of PP2A-B56 $\gamma 1$ inactivation. To determine the significance of the inactivation of PP2A-B56 $\gamma 1$ phosphatase activity, we next analysed the kinetics of MEK phosphorylation. It is well established that MEK is a dual kinase that is required for ERK activation. The kinetics of MEK activation was determined by western blotting of the active form of MEK, which is MEK that is phosphorylated at Ser ${ }^{217 / 221}$ (pMEK), using the same cell lysates as those used for analysis of the early kinetics of pTpYERK. Similar to pTpYERK, the level of pMEK also reached a maximum at $5 \mathrm{~min}$ after the start of stimulation. The level of pMEK decreased more rapidly than the level of pTpYERK (Figure 7B). The combined data suggest that inactivation of PP2A-B56 $\gamma 1$ prior to the initiation of MEK and ERK phosphorylation could be involved in transmission of the signal from MEK to ERK.

The subsequent changes in PP2A-B56 $\gamma 1$ activity over time presumably affect the phosphorylation of ERK as follows. After activated MEK has fully phosphorylated ERK at $5 \mathrm{~min}$ and pMEK has decreased, ERK phosphorylation would still be increasing as a consequence of overall MEK activity, even if the level was low, unless PP2A-B56 $\gamma 1$ was able to access pTpYERK. The activity of PP2A-B56 $\gamma 1$ at $15 \mathrm{~min}$ after stimulation, which had recovered to half the original level of activity at time 0 , would decrease the MEK-induced phosphorylation of ERK at $15 \mathrm{~min}$. Indeed MEK phosphorylation had decreased to half the peak value by $15 \mathrm{~min}$. Therefore, the level of ERK phosphorylation would be maintained at the same level due to the balance of the opposing actions of MEK1 and PP2A-B56 $\gamma 1$.

\section{Discussion}

McGright et al. [68] reported that $\mathrm{B} 56 \alpha \mathrm{l}$ and $\mathrm{B} 56 \beta 1$ are localized in cytoplasm, and that B56 $\gamma 1$ is concentrated in nuclei. Other studies have reported that B56 $\gamma 1$ is localized in focal contacts together with paxillin [46] and also in the Golgi complex [63]. These conflicting data regarding the localization of B56 $\gamma 1$ may have led to misinterpretation of its functions. However, we confirmed here that B56 $\gamma 1$ is localized in nuclei by means of a confocal laser scanning microscopic study using the same antimouse B56 $\gamma 1$ antibody and the same animal species as those used by Ito et al. $[46,63]$. The reported difference in B56 $\gamma 1$ localization between their work and ours could be due to the presence or absence of stimulation. Furthermore, B56 $\gamma 1$ inhibited migration, formed a complex with pTpYERK, probably together with the A and $\mathrm{C}$ subunits of PP2A, and dephosphorylated pTpYERK in cell lysates. Among the results obtained in the present study, we could not detect association of B56 $\gamma 1$ and pTpYERK by immunofluorescence but by pulldown assay. The enzyme-substrate reaction should be prompt as the immunofluorescence could not detect the association. However, the reaction should not have been completed so promptly, and the unreacted substrates could have been observed by the pulldown assay. Thus, B $56 \gamma 1$ functions to regulate nuclear ERK activation through dephosphorylation at the TEY motif.

The combined results of the present study showed that there is an interaction between IER3 and PP2A-B56 $\gamma 1$, which results in IER3-mediated inhibition of the dephosphorylation of pTpYERK, thereby leading to sustained ERK activation in the nucleus and cell migration. Our findings reveal two important aspects of IER3 regulatory function towards B56 $\gamma 1$. First, we showed that IER3 expression started within a few minutes after stimulation. Second, we showed that the kinetics both of sustained ERK activation and augmented IER synthesis were caused by costimulation of EGF and collagen adhesion. Sustained ERK activation is likely to be caused indirectly via the effect of augmented IER 3 synthesis on PP2A-B56 $\gamma 1$ activity, since an inhibitory effect of IER3 on PP2A$\mathrm{B} 56 \gamma 1$ activity via release of the $\mathrm{C}$ subunit has already been reported by Letourneux et al. [39]. The expression of IER3 in costimulated cells was higher than that in the cells stimulated with EGF alone, possibly due to the greater ERK activation. The expression level is high enough to prevent ERK dephosphorylation in conjunction with decreased but still substantial MEK activity, leading to sustained activation of ERK in a positive feedback manner.

The kinetics of PP2A-B56 $\gamma 1$ activity suggested that the observed inactivation of PP2A-B56 $\gamma 1$ phosphatase was caused by two different mechanisms. The later phase of phosphatase inactivation could be due to newly synthesized IER3 (Figure 7A right upper triangle demarcated by dotted lines), which induces sustained activation of ERK leading to cell migration. On the other hand, PP2A-B56 $\gamma 1$ activity was lost rapidly in the earlier phase. Considering that there is a background level of phosphatase activity of PP2A-B56 $\gamma 1$ at $0 \mathrm{~min}$ in Calul carcinoma cells, one possibility is that the extinction of PP2A-B56 $\gamma 1$ activity in the early phase might be important to achieve stable signalling for induction of ERK phosphorylation. Unless constitutively active PP2A-B56 $\gamma 1$ was inactivated, as found in the present study, ERK phosphorylation would be influenced by PP2A-B56 $\gamma 1$ activity. This situation would result in a decrease in the level of pTpYERK and also in an unstable signal dependent upon background phosphatase activities. Thus, the transient extinction of PP2A may play a passive but extremely important role in ensuring the fidelity of the strength of ERK activation. The rapid inhibition of PP2AB56 $\gamma 1$ activity might be the same event as previously reported $[69,70]$; in that work, Src transiently inactivated the phosphatase activity of PP2A by phosphorylation of the $\mathrm{C}$ subunit at $\mathrm{Tyr}^{307}$, leading to dissociation of the $\mathrm{C}$ subunit from PP2A heterotrimer [70]. However, it was also noted that the peak of inactivation of PP2A was at $15 \mathrm{~min}$ after stimulation [70]. If that were the case, the significance of the phenomenon would be totally different from what we suggest here, as they claimed that the transient deactivation of PP2A might enhance transmission of the cellular signal [69]. However, the time lag in their case might have been due to their experimental procedure. If the reported inactivation signal from Src was the same signal as the immediate inactivation of PP2A in the present study, it could have originated both from growth factor receptor and integrin, since it has been reported that a growth factor receptor caused PP2A deactivation through Src [69] and Src is involved in integrin-generated signals [71]. Thus, the immediate robust inactivation of PP2A-B56 $\gamma 1$ could be due to transient phosphorylation/inactivation of PP2A (Figure 7A left area demarcated by dotted lines and a solid line), and the synergistic Src-PP2A-ERK signal should be synchronized to the 
synergistic MEK-ERK signal from growth factor and integrinmediated anchorage [16].

The PP2A B56 $\gamma$ gene encodes four differentially spliced forms, PP2A-B56 $\gamma 1, \gamma 2, \gamma 3$ and $\gamma 4$. Amino acids of the spliced variants are identical until exon 12, and B56 $\gamma 2, \gamma 3$, and $\gamma 4$ have an additional exon or exons [72,73]. In regard to a specific binding domain, they all have the same amino acids from 391 to 402, which constitute a domain required for interaction with p53 [49]. Indeed, PP2A-B56 $\gamma 1, \gamma 2$ nd $\gamma 3$ have been reported to dephosphorylate p53 protein at Ser15 [48,49,74]. Similarly, all the $\gamma$ variants could be plausible to bind to ERK as the present study showed that B56 11 bound to and phosphorylated ERK. Presumably, B56 11 have a specific binding site to ERK, which has not been determined yet. In addition, other isoforms of B subunit might phosphorylate ERK in the cytoplasm as PP2AB56 $\gamma 1$ did in the nucleus, since phosphorylated ERK localizes not only in the nucleus but anywhere in the cytoplasm [4].

\section{Conclusions}

Our results indicate that the strength and duration of ERK activity are regulated by a combination of MEK and PP2A-B56 $\gamma 1$

\section{References}

1. Anderson NG, Maller JL, Tonks NK, Sturgill TW (1990) Requirement for integration of signals from two distinct phosphorylation pathways for activation of MAP kinase. Nature 343: 651-653.

2. Gomez N, Cohen P (1991) Dissection of the protein kinase cascade by which nerve growth factor activates MAP kinases. Nature 353: 170-173.

3. Crews CM, Alessandrini A, Erikson RL (1992) The primary structure of MEK, a protein kinase that phosphorylates the ERK gene product. Science 258: 478480.

4. Wortzel I, Seger R (2011) The ERK Cascade: Distinct functions within various subcellular organelles. Genes Cancer 2: 195-209.

5. Murphy LO, Blenis J (2006) MAPK signal specificity: the right place at the right time. Trends Biochem Sci 31: 268-275.

6. Sacks DB (2006) The role of scaffold proteins in MEK/ERK signalling. Biochem Soc Trans 34: 833-836.

7. Brandman O, Meyer T (2008) Feedback loops shape cellular signals in space and time. Science 322: 390-395.

8. Fowler T, Sen R, Roy AL (2011) Regulation of primary response genes. Mol Cell 44: 48-60.

9. Traverse S, Gomez N, Paterson H, Marshall C, Cohen P (1992) Sustained activation of the mitogen-activated protein (MAP) kinase cascade may be required for differentiation of PC12 cells Comparison of the effects of nerve growth factor and epidermal growth factor. Biochem J 288: 351-355.

10. Marshall CJ (1995) Specificity of receptor tyrosine kinase signalling: transient versus sustained extracellular signal-regulated kinase activation. Cell 80: 179 185.

11. Weber JD, Raben DM, Phillips PJ, Baldassare JJ (1997) Sustained activation of extracellular-signal-regulated kinase 1 (ERK1) is required for the continued expression of cyclin D1 in G1 phase. Biochem J 326: 61-68.

12. Morino N, Mimura T, Hamasaki K, Tobe K, Ueki K, et al. (1995) Matrix/ integrin interaction activates the mitogen-activated protein kinase, p44erk-1 and p42erk-2. J Biol Chem 270: 269-273.

13. Kahan G, Seuwen K, Meloche S, Pouyssegur J (1992) Coordinate, biphasic activation of $\mathrm{p} 44$ mitogen-activated protein kinase and $\mathrm{S} 6$ kinase by growth factors in hamster fibroblasts Evidence for thrombin-induced signals different from phosphoinositide turnover and adenylylcyclase inhibition. J Biol Chem 267: 13369-13375.

14. Miyamoto S, Teramoto H, Gutkind JS, Yamada KM (1996) Integrins can collaborate with growth factors for phosphorylation of receptor tyrosine kinases and MAP kinase activation: roles of integrin aggregation and occupancy of receptors. J Cell Biol 135: 1633-1642.

15. Eliceiri BP, Klemke R, Stromblad S, Cheresh DA (1998) Integrin $\alpha_{\mathrm{v}} \beta 3$ requirement for sustained mitogen-activated protein kinase activity during angiogenesis. J Cell Biol 140: 1255-1263.

16. Kawahara E, Nakada N, Hikichi T, Kobayashi J, Nakanishi I (2002) EGF and $\beta 1$ integrin convergently regulate migration of A431 carcinoma cell through MAP kinase activation. Exp Cell Res 272: 84-91.

17. Howe AK, Aplin AE, Juliano RL (2002) Anchorage-dependent ERK signalingmechanisms and consequences. Curr Opin Genet Dev 12: 30-35.

18. Tian YC, Chen YC, Chang CT, Hung CC, Wu MS, et al. (2007) Epidermal growth factor and transforming growth factor- $\beta 1$ enhance HK-2 cell migration through a synergistic increase of matrix met alloproteinase and sustained activation of ERK signaling pathway. Exp Cell Res 313: 2367-2377. activities. We propose that the machinery of the spatio-temporal regulation of ERK is as illustrated in Figure 8. First, MEK activates ERK (Figure 8-1). The ERK activity transmitted by MEK is initially unaffected by B56 1 1-PP2A due to its prompt extinction (Figure 8-2), but subsequently the balance of MEK and B56 $\gamma 1$-PP2A activities determines the strength of ERK activation. A positive feedback loop involving IER3-B56 $\gamma$ l-phosphorylated ERK (Figure 8-3) determines the duration of ERK activation.

\section{Acknowledgments}

We thank Dr. David Virshup for kindly providing pCEPB56 $\beta 1$, pCEPB56 $\beta 1$, pCEP56 $\gamma 1$, Dr. Hiroshi Nojima for anti-mouse B56 $\gamma 1$ antibodies, and Dr. Akihiko Ito for pCX4bsrB56 $\gamma 1$. We also thank Yuka Hattori, Tomokatsu Kanitani, Misa Takayanagi, Kaori Sakano, Rika Ubasawa, and Megumi Hamada for their technical assistance.

\section{Author Contributions}

Conceived and designed the experiments: EK. Performed the experiments: EK SM ES YN HS. Analyzed the data: EK SM ES YN HS. Contributed reagents/materials/analysis tools: EK. Wrote the paper: EK.

19. Roovers K, Davey G, Zhu X, Bottazzi ME, Assoian RK (1999) $\alpha 5 \beta 1$ integrin controls cyclin D1 expression by sustaining mitogen-activated protein kinase activity in growth factor-treated cells. Mol Biol Cell 10: 3197-3204.

20. Bonni A, Brunet A, West AE, Datta SR, Takasu MA, et al. (1999) Cell survival promoted by the Ras-MAPK signaling pathway by transcription-dependent and -independent mechanisms. Science 286: 1358-1362.

21. Murphy LO, MacKeigan JP, Blenis J (2004) A network of immediate early gene products propagates subtle differences in mitogen-activated protein kinase signal amplitude and duration. Mol Cel Biol 24: 144-153.

22. Joslin EJ, Opresko LK, Wells A, Wiley HS, Lauffenburger DA (2007) EGFreceptor-mediated mammary epithelial cell migration is driven by sustained ERK signaling from autocrine stimulation. J Cell Sci 120: 3688-3699.

23. Murphy LO, Smith S, Chen RH, Fingar DC, Blenis J (2002) Molecular interpretation of ERK signal duration by immediate early gene products. Nat Cell Biol 4: 556-564.

24. Sun H, Charles CH, Lau LF, Tonks NK (1993) MKP-1 (3CH134), an immediate early gene product, is a dual specificity phosphatase that dephosphorylates MAP kinase in vivo. Cell 75: 487-493.

25. Alessi DR, Gomez N, Moorhead G, Lewis T, Keyse SM, et al. (1995) Inactivation of p42 MAP kinase by protein phosphatase $2 \mathrm{~A}$ and a protein tyrosine phosphatase, but not CL100, in various cell lines. Curr Biol 5: 283-295.

26. Chajry N, Martin PM, Cochet C, Berthois Y (1996) Regulation of p42 mitogenactivated-protein kinase activity by protein phosphatase $2 \mathrm{~A}$ under conditions of growth inhibition by epidermal growth factor in A431 cells. Eur J Biochem 235: 97-102.

27. Brondello JM, Pouyssegur J, McKenzie FR (1999) Reduced MAP kinase phosphatase-1 degradation after p42/p44MAPK-dependent phosphorylation. Science 286: 2514-2517.

28. Gronda M, Arab S, Iafrate B, Suzuki H, Zanke BW (2001) Hematopoietic protein tyrosine phosphatase suppresses extracellular stimulus-regulated kinase activation. Mol Cell Biol 21: 6851-6858.

29. Noordman YE, Jansen PA, Hendriks WJ (2006) Tyrosine-specific MAPK phosphatases and the control of ERK signaling in PC12 cells. J Mol Signal 1: 4.

30. Hashigasako A, Machide M, Nakamura T, Matsumoto K, Nakamura T (2004) Bi-directional regulation of Ser-985 phosphorylation of c-met via protein kinase $\mathrm{C}$ and protein phosphatase $2 \mathrm{~A}$ involves c-Met activation and cellular responsiveness to hepatocyte growth factor. J Biol Chem 279: 26445-26452.

31. van Kanegan MJ, Strack S (2009) The protein phosphatase 2A regulatory subunits $\mathrm{B}^{\prime} \beta$ and $\mathrm{B}^{\prime} \delta$ mediate sustained TrkA neurotrophin receptor autophosphorylation and neuronal differentiation. Mol Cell Biol 29: 662-674.

32. Ugi S, Imamura T, Ricketts W, Olefsky JM (2002) Protein phosphatase 2A forms a molecular complex with She and regulates Shc tyrosine phosphorylation and downstream mitogenic signaling. Mol Cell Biol 22: 2375-2387.

33. Abraham D, Podar K, Pacher M, Kubicek M, Welzel N, et al. (2000) Raf-1associated protein phosphatase $2 \mathrm{~A}$ as a positive regulator of kinase activation. J Biol Chem 275: 22300-22304.

34. Ory S, Zhou M, Conrads TP, Veenstra TD, Morrison DK (2003) Protein phosphatase $2 \mathrm{~A}$ positively regulates Ras signaling by dephosphorylating KSR 1 and Raf-1 on critical 14-3-3 binding sites. Curr Biol 13: 1356-13564.

35. Adams DG, Coffee RL, Zhang H, Pelech S, Strack S, et al. (2005) Positive regulation of Rafl-MEK1/2-ERK1/2 signalling by protein serine/threonine phosphatase 2A holoenzymes. J Biol Chem 280: 42644-42654. 
36. Mao L, Yang L, Arora A, Choe ES, Zhang G, et al. (2005) Role of protein phosphatase 2A in mGluR5-regulated MEK/ERK phosphorylation in neurons. J Biol Chem 280: 12602-12610.

37. Bae D, Ceryak S (2009) Raf-independent, PP2A-dependent MEK activation in response to ERK silencing. Biochem Biophys Res Commun 385: 523-527.

38. Zhou B, Wang ZX, Zhao Y, Brautigan DL, Zhang ZY (2002) The specificity of extracellular signal-regulated kinase 2 dephosphorylation by protein phosphatases. J Biol Chem 277: 31818-31825.

39. Letourneux C, Rocher G, Porteu F (2006) B56-containing PP2A dephosphorylate ERK and their activity is controlled by the early gene IEX-1 and ERK. EMBO J 25: 727-738.

40. Janssens V, Goris J, van Hoof C (2005) PP2A: the expected tumor suppressor. Curr Opin Genet 15: 34-41.

41. Ruediger R, Pham HT, Walter G (2007) Disruption of protein phosphatase 2A subunit interaction in human cancers with mutations in the A $\alpha$ subunit gene. Oncogene 20: 10-15.

42. Eichhorn PJ, Creyghton MP, Bernards R (2009) Protein phosphatase 2A regulatory subunits and cancer. Biochim Biophys Acta 1: 1-15.

43. Young MR, Lozano Y, Djorjevic A, Maier GD (1993) Protein phosphatases limit tumor motility. Int J Cancer 54: 1036-1041.

44. Maier GD, Wright MA, Lozano Y, Djordjevic A, Matthews JP, et al. (1995) Regulation of cytoskeletal organization in tumor cells by protein phosphatases-1 and -2A. Int J Cancer 61: 54-61.

45. Rocher G, Letourneux C, Lenormand P, Porteu F (2007) Inhibition of B56containing protein phosphatase $2 \mathrm{As}$ by the early response gene IEX-1 leads to control of Akt activity. J Biol Chem 282: 5468-5477.

46. Ito A, Kataoka TR, Watanabe M, Nishiyama K, Mazaki Y, et al. (2000) A truncated isoform of the PP2A B56 subunit promotes cell motility through paxillin phosphorylation. EMBO J 19: 562-571.

47. Koma YI, Koma YI, Ito A, Watabe K, Kimura SH, et al., (2004) A truncated isoform of the PP2A B56 $\gamma$ regulatory subunit reduces irradiation-induced Mdm2 phosphorylation and could contribute to metastatic melanoma cell radioresistance. Histol Histopathol 19: 391-400.

48. Li HH, Cai X, Shouse GP, Piluso LG, Liu X (2007) A specific PP2A regulatory subunit, B56\%, mediates DNA damage-induced dephosphorylation of p53 at Thr55. EMBO J 26: 402-411.

49. Shouse GP, Nobumori Y, Liu X (2010) A B56 $\gamma$ mutation in lung cancer disrupts the p53-dependent tumor-suppressor function of protein phosphatase $2 \mathrm{~A}$. Oncogene 29: 3933-3941.

50. Ma J, Arnold HK, Lilly MB, Sears RC, Kraft AS (2007) Negative regulation of Pim-1 protein kinase levels by the B56 $\beta$ subunit of PP2A. Oncogene 26: 51455153.

51. Saraf A, Virshup DM, Strack S (2007) Differential expression of the $B^{\prime} \beta$ regulatory subunit of protein phosphatase $2 \mathrm{~A}$ modulates tyrosine hydroxylase phosphorylation and catecholamine synthesis. J Biol Chem 282: 573-580.

52. Padmanabhan S, Mukhopadhyay A, Narasimhan SD, Tesz G, Czech MP, et al. (2009) A PP2A regulatory subunit regulates C. elegans insulin/IGF-1 signaling by modulating AKT-1 phosphorylation. Cell 136: 939-951.

53. Rodgers JT, Vogel RL, Puigserver P (2011) Clk2 and B56 3 mediate insulinregulated assembly of the PP2A phosphatase holoenzyme complex on Akt. Mol Cell 41: 471-479.

54. Isoda M, Sako M, Suzuki K, Nishino K, Nakajo N, et al. (2011) Dynamic regulation of Emi2 by Emi2-bound Cdk1/Plk1/CK1 and PP2A-B56 in meiotic arrest of Xenopus eggs. Dev Cell 21: 506-519.

55. Bhasin N, Cunha SR, Cunha SR, Mudannayake M, Gigena MS, et al. (2007) Molecular basis for PP2A regulatory subunit B56 $\alpha$ targeting in cardiomyocytes. Am J Physiol Heart Circ Physiol 293: 109-119.

56. Pitman MR, Barr RK, Gliddon BL, Magarey AM, Moretti PA, et al. (2011) A critical role for the protein phosphatase $2 \mathrm{~A} \mathrm{~B}^{\prime} \alpha$ regulatory subunit in dephosphorylation of sphingosine kinase 1. Int J Biochem Cell Biol 43: 342-347.
57. Dozier C, Bonyadi M, Baricault L, Tonasso L, Darbon JM (2004) Regulation of Chk2 phosphorylation by interaction with protein phosphatase $2 \mathrm{~A}$ via its $\mathrm{B}^{\prime}$ regulatory subunit. Biol Cell 96: 509-517.

58. Mukhopadhyay NK, Gilchrist D, Gordon GJ, Chen CJ, Bueno R, et al. (2004) Integrin-dependent protein tyrosine phosphorylation is a key regulatory event in collagen-IV-mediated adhesion and proliferation of human lung tumor cell line, Calu-1. Ann Thorac Surg 78: 450-457.

59. Kawahara E, Yasunori O, Nakanishi I, Kazushi I, Kojima S, et al. (1993) The expression of invasive behaviour of differentiated squamous cell carcinoma cell line evaluated by an in vitro invasion model. Jpn J Cancer Res 84: 409-418.

60. Kawahara E, Tokuda R, Nakanishi I (1999) Migratory phenotype of HSC-3 squamous carcinoma cell line induced by EGF and PMA: Relevance to migration of loosening of adhesion and vinculin-associated focal contacts with prominent filopodia. Cell Biol Int 23: 163-174.

61. Yebra M, Filard EJ, Bayna EM, Kawahara E, Becker JC, et al. (1995) Induction of carcinoma cell migration on vitronectin by NF- $\kappa \mathrm{B}$-dependent gene expression. Mol Biol Cell 6: 841-850.

62. Seeling JM, Miller JR, Gil R, Moon RT, White R, et al. (1999) Regulation of beta-catenin signaling by the B56 subunit of protein phosphatase 2A. Science 283: 2089-2091.

63. Ito A, Koma Y, Sohda M, Watanabe K, Nagano T, et al. (2003) Localization of the PP2A B56ZZZ regulatory subunit at the Golgi complex Possible role in vesicle transport and migration. Am J Pathol 162: 479-489.

64. Kawahara E, Saito A, Kobayashi J, Maenaka S, Minamoto T, et al. (2005) Adhesiveness of $\beta 5$ integrin variant lacking FNK767-769 is similar to that of the prototype containing FNKFNK764-769. Cell Biol Int 29: 521-528.

65. Nakada N, Kuroda K, Kawahara E (2005) Protein phosphatase 2A regulatory subunit B $\beta$ promotes MAP Kinase-mediated migration of A431 cells. Cell Physiol Biochem 15: 19-28.

66. Garcia J, Ye Y, Arranz V, Letourneux C, Pezeron G, et al. (2002) IEX-1: a new ERK substrate involved in both ERK survival activity and ERK activation. EMBO J 21: 5151-5163.

67. Charles CH, Yoon JK, Simske JS, Lau LF (1993) Genomic structure, cDNA sequence, and expression of gly96, a growth factor-inducible immediate-early gene encoding a short-lived glycosylated protein. Oncogene 8: 797-801.

68. McCright B, Rivers AM, Audlin S, Virshup DM (1996) The B56 family of protein phosphatase 2A (PP2A) regulatory subunits encodes differentiationinduced phosphoproteins that target PP2A to both nucleus and cytoplasm. J Biol Chem 271: 22081-22089.

69. Chen J, Martin BL, Brautigan DL (1992) Regulation of protein serine-threonine phosphatase type-2A by tyrosine phosphorylation. Science 257: 1261-1264.

70. Chen J, Parsons S, Brautigan DL (1994) Tyrosine phosphorylation of protein phosphatase 2A in response to growth stimulation and $\mathrm{v}$-src transformation of fibroblasts. J Biol Chem 269: 7957-7962.

71. Schlaepfer DD, Broome MA, Hunter T (1997) Fibronectin-stimulated signaling from a focal adhesion kinase-c-Src complex: involvement of the Grb2, p130cas, and Nck adaptor proteins. Mol Cell Biol 17: 1702-1713.

72. Ortega-Lazaro JC, del Mazo J (2003) Expression of the B56 $\delta$ subunit of protein phosphatase $2 \mathrm{~A}$ and Meal in mouse spermatogenesis. Identification of a new B56 $\gamma$ subunit (B56 $\gamma 4$ ) specifically expressed in testis. Cytogenet Genome Res 103: 345-351.

73. Muneer S, Ramalingam V, Wyatt R, Schultz RA, Minna JD et al. (2002) Genomic organization and mapping of the gene encoding the PP2A B56 $\gamma$ regulatory subunit. Genomics 79: 344-348.

74. Shouse GP, Cai X, Liu X (2008) Serine 15 phosphorylation of p53 directs its interaction with B56 $\gamma$ and the tumor suppressor activity of B56 $\gamma$-specific protein phosphatase 2A. Mol Cell Biol 28: 448-456. 